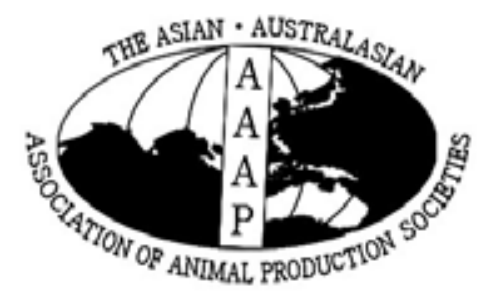

Asian-Aust. J. Anim. Sci.

Vol. 20, No. $1: 60$ - 69

January 2007

www.ajas.info

\title{
Physiological Factors Depressing Feed Intake and Saliva Secretion in Goats Fed on Dry Forage
}

\author{
K. Sunagawa*, T. Ooshiro, N. Nakamura, Y. Ishii, I. Nagamine and A Shinjo \\ Faculty of Agriculture, University of the Ryukyus, 1 Senbaru, Nishihara-cho, Okinawa 903-0213, Japan
}

\begin{abstract}
Ruminants eating dry forage secrete large volumes of saliva which results in decreased plasma volume (hypovolemia) and the loss of $\mathrm{NaHCO}_{3}$ from the blood. The present research investigated whether or not hypovolemia and the loss of $\mathrm{NaHCO}_{3}$ from the blood in goats brought about by dry forage feeding actually depresses feed intake and saliva secretion, respectively. The present experiment consisted of three treatments (NI, ASI, MI). In the control treatment (NI), a solution was not infused. In the ASI treatment, i.v. infusion of artificial parotid saliva was initiated $1 \mathrm{~h}$ before feeding and continued for the entire $2 \mathrm{~h}$ feeding period. In the MI treatment, iso-osmotic mannitol solution was infused. The NI treatment showed that hematocrit and plasma total protein concentration were increased due to decreased circulating plasma volume brought about by feeding. In the ASI treatment, the fluid and $\mathrm{NaHCO}_{3}$ that were lost from the blood because of a feeding-induced acceleration of saliva secretion was replenished with an intravenous infusion of artificial parotid saliva. This replenishment lessened the levels of suppression on both feeding and parotid saliva secretion. When only the lost fluid was replenished with an intravenous infusion of iso-osmotic mannitol solution in the MI treatment, the degree of feeding suppression was lessened but the level of saliva secretion suppression was not affected. These results indicate that the marked suppression of feed intake during the initial stages of dry forage feeding was caused by a feeding-induced hypovolemia while the suppression of saliva secretion was brought about by the loss of $\mathrm{NaHCO}_{3}$ from the blood due to increased saliva secretion during the initial stages of feeding. (Key Words : Dry Forage Intake, Saliva Secretion, Feeding Induced Hypovolemia, Goats)
\end{abstract}

\section{INTRODUCTION}

Campling and Balch (1961), and Anil et al. (1993) reported that when a balloon was inserted into the rumen to restrict the rumen capacity of cows fed on hay and silage, feed intake was decreased. Hidari (1981) found that when sheep with free access to hay reached a certain level of rumen fill, they stopped feeding. However, Kato (1977) compared feeding duration and feed intake in sheep with an esophageal fistula under normal feeding and sham feeding conditions whereby ingested matter was removed from the fistula after eating. Feeding duration and feed intake of fresh grass and hay under sham feeding conditions were not significantly different from those under normal feeding conditions whereby ingested matter was allowed to enter the rumen. This result suggested that some extraruminal mechanisms exist to suppress grass intake.

It was reported that the intake of alfalfa pellets was regulated by changes in ruminal fluid osmolality (Bail et al.,

\footnotetext{
* Corresponding Author: K. Sunagawa. Tel: +81-98-895-8798, Fax: +81-98-895-8734, E-mail: b986094@agr.u-ryukyu.ac.jp Received August 12, 2005; Accepted January 19, 2006
}

1969; Grovum, 1995; Kato et al., 1979). The equal dose (in moles) of hyper-osmotic $\mathrm{NaCl}$, polyethylene glycol-400 (PEG), sodium acetate or sodium propionate produced the same respective increases in rumen fluid osmolality when intraruminally infused. These increases in rumen fluid osmolality resulted in the same sized decrease in feed intake (Grovum, 1995). On the other hand, when the ruminal fluid osmolality was decreased by the intraruminal infusion of an excessive amount of warm water $\left(39.8^{\circ} \mathrm{C}\right)$ in sheep fed on alfalfa hay cubes, feed intake increased $30 \%$ (Sunagawa et al., 2002a). However, the effect of internal humoral (circulating blood) factors on the intake of dry forage has not been investigated under these experimental conditions. The nature of rumen osmoreceptors remains to be determined (Forbes and Barrino, 1992), and there is no biological proof of the existence of osmoreceptors in rumen walls that are sensitive to physiological variations in osmotic pressure (Cater and Grovum, 1990).

When ruminants commence feeding of dry forage they secrete copious volumes of parotid saliva (Sato, 1975; Sunagawa et al., 2002a; Sunagawa et al., 2003). Ruminant saliva is particularly rich in $\mathrm{NaHCO}_{3}$. Saliva acts as a 
Table 1. Physiological parameters in goats prior to (NP) and after (P) parotid fistulation

\begin{tabular}{lcc}
\hline & \multicolumn{1}{c}{$\mathrm{NP}$} & \multicolumn{1}{c}{$\mathrm{P}$} \\
\hline Water intake (ml/day) & $6,921 \pm 1,141$ & $6,327 \pm 1,076$ \\
Urine excretion (ml/day) & $5,441 \pm 910$ & $4,477 \pm 847$ \\
Plasma osmolality (mOsm/L) & $288.0 \pm 2.13$ & $288.7 \pm 2.16$ \\
Plasma total protein (g/dL) & $7.3 \pm 0.17$ & $7.1 \pm 0.19$ \\
Hematocrit (\%) & $27.8 \pm 0.56$ & $29.9 \pm 0.64$ \\
Plasma Na (mmol/L) & $145.2 \pm 1.23$ & $145.5 \pm 0.92$ \\
Plasma K (mmol/L) & $4.6 \pm 0.09$ & $4.6 \pm 0.17$ \\
Plasma Cl (mmol/L) & $109.6 \pm 0.58$ & $107.9 \pm 1.53$
\end{tabular}

Parotid saliva flowing from the parotid fistula was collected in a plastic bucket. Prior to the morning feeding, the collected saliva was infused into the rumen via the extension tube using a bathtub pump. Values are mean \pm S.E. of 7 goats.

lubricant in the mouth and esophagus, supplies fluid to the non-secretory rumino-reticulum, and serves to buffer decreases in $\mathrm{pH}$ due to the volatile fatty acid production of microbial fermentation in the rumen. However, during the initial stages of feeding, large amounts of fluid and $\mathrm{NaHCO}_{3}$ move from the circulating blood into the rumen in the form of saliva. Blair-West and Brook (1969) found that sheep fed lucerne chaff once a day showed a marked reduction in plasma volume within $15 \mathrm{~min}$ of the commencement of feeding. Sasaki et al. (Sasaki et al., 1974; Sasaki et al., 1975) reported that sheep fed once a day on orchard grass hay showed significant decrease in plasma bicarbonate concentration which resulted in a decrease in blood $\mathrm{pH}$ during initial stages of feeding. However, the effects of these internal humoral factors on the intake of dry forage have not been the focus of investigations to date. In the present study, it is hypothesized that a feeding-induced hypovolemia (decrease of plasma volume) plays an important role in the regulation of dry forage intake and saliva secretion volumes.

\section{MATERIALS AND METHODS}

\section{Animals}

Seven male goats (1 Japanese Saanen goat, 6 yr old, weighing $72.5 \mathrm{~kg}$; 6 crossbred Japanese Saanen/Nubian male goats, 4 to $6 \mathrm{yr}$, weighing $82.8 \pm 3.7 \mathrm{~kg}$ ) were used in this experiment. In order to collect parotid saliva, the apertura of one of the parotid ducts was surgically prepared to exteriorize it via the cheek of the animal more than 6 months prior to the experiment. Either an Atom Disposable Multiple Purpose Tube (o.d. 2.75 mm, 8 fr, Atom, Tokyo) approximately $10 \mathrm{~cm}$ in length or, depending on the animal, a fluid infusion tube (o.d. $4.00 \mathrm{~mm}$, Terumo, Tokyo) was inserted into the parotid duct and fixed to the cheek. To enable the return of saliva collected from the parotid fistula, an extension tube (o.d. $4.50 \mathrm{~mm}$, X3-50, Top, Tokyo) was inserted into the dorsal sac of the rumen. The other end of the tube was fixed to the skin. Parotid saliva flowing from
Table 2. Chemical composition of alfalfa hay cubes and ground concentrate feed

\begin{tabular}{lcc}
\hline & $\begin{array}{c}\text { Alfalfa } \\
\text { hay cube }\end{array}$ & $\begin{array}{c}\text { Ground } \\
\text { concentrate feed }\end{array}$ \\
\hline Dry matter (\%) & 84.3 & 86.9 \\
Chemical composition (\% of DM) & & \\
$\quad$ Crude protein & 18.7 & 13.4 \\
Crude fat & 2.4 & 3.6 \\
Crude fiber & 29.7 & 3.7 \\
Nitrogen-free extracts (NFE) & 39.7 & 71.0 \\
NDF & 45.9 & 14.6 \\
ADF & 36.6 & 5.4 \\
Na & 0.10 & 0.25 \\
K & 2.39 & 0.71 \\
Cl & 0.47 & 0.31 \\
Ca & 1.40 & 0.78 \\
Mg & 0.29 & 0.25 \\
P & 0.23 & 0.48 \\
\hline
\end{tabular}

DM: dry matter. NDF: neutral detergent fiber. ADF: acid detergent fiber.

the parotid fistula was collected in a plastic bucket. The goats were maintained in individual metabolic cages (length $2 \mathrm{~m} \times$ width $1 \mathrm{~m} \times$ height $2 \mathrm{~m}$ ) that allowed for the separate collection of urine, feces and saliva. The laboratory room

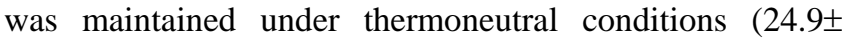
$0.1^{\circ} \mathrm{C}, 76.5 \pm 1.3 \%$ relative humidity).

The animals were fed twice a day at 10:30 and again at 16:00 for $2 \mathrm{~h}$ each time. Prior to the morning feeding, the collected saliva (3 to $5 \mathrm{~kg}$ ) was infused into the rumen via the extension tube using a bathtub pump (Minipandy, KP30F, Koshin, Tokyo). The physiological state of the goats used in this experiment was not changed after parotid gland fistulation because the collected saliva was infused into the rumen every day (Table 1). During the morning $2 \mathrm{~h}$ feeding period (10:00 to 12:00), the animals were fed 2 to $3 \mathrm{~kg}$ of roughly crushed $(3 \times 3 \times 1 \mathrm{~cm})$ alfalfa hay cubes. At 16:00 each day, the animals were fed again with $0.8 \mathrm{~kg}$ of alfalfa hay cubes, $200 \mathrm{~g}$ of commercial ground concentrate and 20 g of sodium bicarbonate. When the experiment was not carried out, the animals were given unrestricted access to water.

The chemical composition of the alfalfa hay cubes and ground concentrate feed is indicated in Table 2. Alfalfa hay cubes were ground with a Wiley mill (type 40-525P, Ikemoto Rika Kougyou, Tokyo, Japan). The chemical components of the feeds were quantified using the procedures described by the Japanese Feed Association (Kato, 1988). The crude protein content was calculated from the nitrogen content of the feed and was determined by a technique originally devised by Kjeldahl (AOAC, 1990). The crude fat was determined by subjecting the feed to a continuous extraction with ethyl ether for $16 \mathrm{~h}$ using a Soxhlet. The crude fiber was determined by subjecting the residual feed from ether extraction to successive treatments with boiling sulfuric acid and sodium hydroxide of $1.25 \%$. 
Table 3. The physiological parameters on days prior to and after treatment

\begin{tabular}{lcccc}
\hline Days & $\begin{array}{c}\text { Respiration frequency } \\
\text { breaths/min }\end{array}$ & $\begin{array}{c}\text { Heart rate } \\
\text { beats/min }\end{array}$ & $\begin{array}{c}\text { Rectal temperature } \\
{ }^{\circ} \mathrm{C}\end{array}$ & $\begin{array}{c}\text { Feed intake } \\
\mathrm{g} \mathrm{DM} / \mathrm{kg} \mathrm{BW}\end{array}$ \\
\hline-2 & $19 \pm 0.7$ & $80 \pm 2.8$ & $38.4 \pm 0.07$ & $26.9 \pm 0.57$ \\
-1 & $19 \pm 0.9$ & $76 \pm 3.2$ & $38.5 \pm 0.07$ & $26.6 \pm 0.60$ \\
Treatment day & $18 \pm 1.0$ & $77 \pm 3.6$ & $38.5 \pm 0.05$ & $22.1 \pm 0.90$ \\
1 & $20 \pm 1.2$ & $73 \pm 2.9$ & $38.4 \pm 0.04$ & $27.0 \pm 0.56$ \\
2 & $20 \pm 1.0$ & $77 \pm 2.7$ & $38.4 \pm 0.05$ & $27.0 \pm 0.77$ \\
3 & $18 \pm 0.7$ & $80 \pm 2.4$ & $38.5 \pm 0.04$ & $27.2 \pm 0.70$ \\
4 & $19 \pm 0.6$ & $78 \pm 2.4$ & $38.6 \pm 0.35$ & $26.6 \pm 0.68$ \\
5 & $19 \pm 1.1$ & $76 \pm 2.8$ & $38.5 \pm 0.05$ & $27.4 \pm 0.52$ \\
6 & $20 \pm 1.0$ & $78 \pm 2.5$ & $38.4 \pm 0.05$ & $26.9 \pm .33$ \\
\hline
\end{tabular}

Values are mean \pm S.E. of 7 goats.

On the treatment day, the animals were not given drinking water during feeding which accounted for the lower level of feed intake.

When the sum of the amount of moisture, ash, crude protein, crude fat and crude fibre was subtracted from 100, the difference was calculated as the nitrogen-free extracts (NFE). The acid-detergent fibre (ADF) and neutraldetergent fibre (NDF) were determined using techniques originally devised by Van Soest (Van Soest, 1991). Both the alfalfa hay cubes and the commercial concentrate were ignited and reduced to ash at $500^{\circ} \mathrm{C}$. The mineral contents of the ash were then measured using an Atomic absorption spectrophotometer (AA-6200, Simazu, Tokyo).

\section{Experiment}

Seven animals were split into three groups of three, two and two goats. Each group received the non-infusion control (NI), the artificial saliva i.v. infusion treatment (ASI), and the iso-osmotic mannitol i.v. infusion treatment (MI) concurrently according to a Latin square design. A minimum recovery period of 1 wk was allowed between each treatment for all the animals (Weisinger et al., 1977). Seven goats were housed in the same room until the experiment had been completed. Each treatment in this research was conducted over a $3 \mathrm{~h}$ period (09:30 to 12:30). On the day of each treatment, the i.v. infusion of artificial saliva or mannitol solution (17 to $19 \mathrm{ml} / \mathrm{min}$ ) was conducted with a motor-driven pump (Cole-Parmer Instrument Co. PA-21, Chicago) over a $3 \mathrm{~h}$ period beginning $1 \mathrm{~h}$ prior to the commencement of morning feeding (09:30) and continuing until feeding completion (12:30). The goats used in this experiment were fed on the same type of feed (alfalfa hay cubes, commercial ground concentrate) from 1 mo prior to the start of experimentation until its conclusion. In order to ascertain the physiological state of the animals, respiration frequency, heart rate, and rectal temperature were measured each day prior to the morning feeding period. In addition to this, feed intake was also measured daily. As illustrated in Table 3, the infusion treatments of the experiment had no effect on physiological parameters the next day. The values of these physiological parameters indicated that an individual animal was in good health and had no measurable carry-over effects from the previous treatments. The data gathered from all 7 goats used in the experiment was statistically analyzed as a repeated measurement.

One day before the commencement of each treatment in the experiment, polyethylene cannulae (o.d. $1.50 \mathrm{~mm}$, No.5, Imamura Gomu, Tokyo) were inserted into the jugular veins on both sides of each goat. One was used for infusion, and the other was used for collecting blood samples. A threeway tap was attached to the end of each cannula. The cannulae were sewn to the skin on animal's back to fix them in place. They were filled with heparin-saline $(50 \mathrm{IU} / \mathrm{ml})$ to prevent coagulation of the blood. On the day of the experiment, the intravenous infusion of artificial parotid saliva or iso-osotic mannitol solution (17 to $19 \mathrm{ml} / \mathrm{min}$ ) was conducted with a motor-driven pump (Cole-Parmer Instrument Co. PA-21, Chicago) over a $3 \mathrm{~h}$ period beginning $1 \mathrm{~h}$ prior to the commencement of morning feeding (09:30) and continuing until feeding completion (12:30). The infusion rate for animals weighing 72.0 and $72.5 \mathrm{~kg}$ was $17.0 \mathrm{ml} / \mathrm{min}$, while the rate for animals weighing 83 to $97 \mathrm{~kg}$ was $19.0 \mathrm{ml} / \mathrm{min}$. The animals were deprived of water during morning feeding on the day of the experiments in the control and both treatments. The withholding of water during morning feeding only on the day of the experiment did not alter the feeding behavior of the goat. In the present experiment, animals were always observed to drink only after feeding first. Feeding was initiated at 10:30 and the animals were fed roughly crushed alfalfa hay cubes for 2 h. Eating rates were determined using a measuring scale. The alfalfa hay cubes (2.0 to 3.0 $\mathrm{kg}$ ) were placed in a feed box attached to a $6 \mathrm{~kg}$ measuring scale. As animals eat the feed, the weight of the remaining feed decreases continuously. The weight of the remaining feed was measured every $10 \mathrm{~min}$ for the duration of the $2 \mathrm{~h}$ feeding period. The decrease in remaining feed as indicated by the scales read every $10 \mathrm{~min}$, was used to calculate feed intake. Figure 1 shows eating rates (g/10 min). Animals were allowed to drink for a $30 \mathrm{~min}$ period immediately 

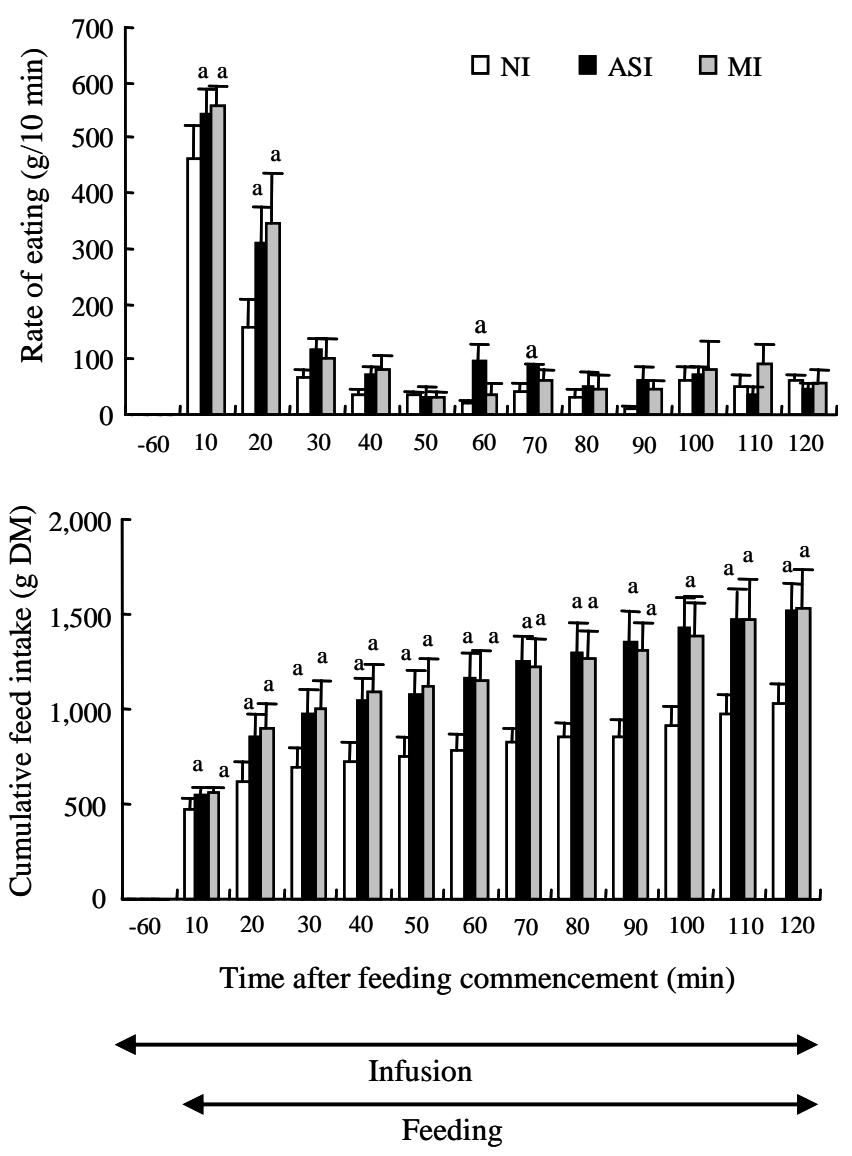

Figure 1. The effects of intravenous infusion of artificial parotid saliva (ASI) or iso-osmotic mannitol solution (MI) on rate of eating and cumulative feed intake. Values are means \pm SE of 7 parotid fistulated goats. a: Means with superscript a differ $(\mathrm{p}<0.05)$ from non-infusion control (NI).

following the conclusion of the $2 \mathrm{~h}$ feeding period. Water intake was calculated by measuring the weight of water in the animal's drinking bucket prior to and then again after the animals had been allowed to drink. The animals were observed to have satisfied their desire to drink within 15 min of the $30 \mathrm{~min}$ drinking period. Blood samples $(5 \mathrm{ml}$ ) were collected through the polyethylene cannula. Prior to drawing the samples, a drop of heparin solution $(1,000$ $\mathrm{IU} / \mathrm{ml}$ ) was placed in a test tube. The blood samples were transferred to these test tubes which were then placed on ice until plasma separation could be carried out. The blood was sampled at 09:30, 10:30, 10:45, 11:00, 11:15, 11:30, 12:00, $12: 30,13: 00$ and 13:15. Blood plasma was obtained by centrifugation $\left(16,260 \times \mathrm{g}, 10 \mathrm{~min}, 4^{\circ} \mathrm{C}\right)$.

The artificial parotid saliva, a solution resembling parotid saliva, consisted of $145 \mathrm{mM} \mathrm{NaHCO} 3,7 \mathrm{mM} \mathrm{KCl}$ and $40 \mathrm{mM} \mathrm{Na} \mathrm{HPO}_{4}$. The mannitol (49.2 g, 270 mmole) was dissolved in sterilized water $(1 \mathrm{~L})$. These solutions had osmolalities of $280 \mathrm{mOsm} / \mathrm{L}$. The $\mathrm{pH}$ values of both solutions were adjusted to 7.4 by bubbling $\mathrm{CO}_{2}$ gas (BlairWest and Brook, 1969; Sasaki et al., 1975). In preliminary experiments, the relationships between cumulative feed intakes over a $2 \mathrm{~h}$ period and infusion rates of 12 to 20 $\mathrm{ml} / \mathrm{min}$ of artificial mixed saliva were examined. It was found that the optimum infusion rates of artificial parotid saliva to increase feed intake were 17 to $19 \mathrm{ml} / \mathrm{min}$. Thus, these rates were adopted for this experiment.

All surgical and experimental procedures were approved by the Animal Experimental Ethics Committee of the University of the Ryukyus and were in compliance with the Japanese code of practice for the care and use of animals for scientific purposes.

\section{Biochemical analysis}

Blood samples were placed in a hematocrit centrifuge (HC-12A, Tomy Seiko, Tokyo, 5 min, 16,260×g) to separate plasma and red blood cells. A hematocrit reader (Tomy Seiko, Tokyo) was used to determine hematocrit. Plasma total protein concentration and osmolality were measured using a refractometer (Atago, Tokyo) and an osmometer (OM-6010, Kyoto Daiichi Kagaku, Kyoto), respectively. The plasma concentrations of $\mathrm{Na}, \mathrm{K}$ and $\mathrm{Cl}$ were measured using Spotchem EL (SE-1520, Arklay, Kyoto).

\section{Statistical analysis}

The parameters for each animal were measured prior to and again after feeding in all three treatments of the experiment (NI, ASI, MI). The measurements were taken, at the same points in time for each animal. The values from these measurements were used to compare the control and the treatments. A two-way analysis (animal, treatment) of variance was performed. After this, Linear comparison was used to compare treatments. For statistical analysis, GLM procedures (SAS Inst., Inc., Cary, NC, 1990) were adopted. Data are presented as means \pm SE of the 7 goats.

All data were analyzed using the following model:

$$
\mathrm{Y}_{\mathrm{ijkl}}=\mu+\alpha_{\mathrm{i}}+\beta_{\mathrm{j}}+\gamma_{\mathrm{k}}+(\beta \gamma)_{\mathrm{jk}}+\varepsilon_{\mathrm{ijkl}}
$$

Where $Y_{i j k l}=a$ value from measurement on the $1^{\text {th }}$ replication of the $\mathrm{i}^{\text {th }}$ animal in the $\mathrm{j}^{\text {th }}$ time and the $\mathrm{k}^{\text {th }}$ treatment; $\mu=$ the overall mean; $\alpha_{i}=$ the effect of the $i^{\text {th }}$ animal;

$\beta_{\mathrm{j}}=$ the effect of the $\mathrm{j}^{\text {th }}$ time; $\gamma_{\mathrm{k}}=$ the effect of the $\mathrm{K}^{\mathrm{th}}$ treatment; $(\beta \gamma)_{\mathrm{jk}}=$ the interaction effect between time and treatment; $\varepsilon_{\mathrm{ijkl}}=$ the random error effect.

\section{RESULTS}

\section{Rate of eating and cumulative feed intake}

Figure 1 shows the effects of ASI or MI treatment on the rate of eating and cumulative feed intake. Eating rates in the NI control were rapidly decreased in the first $30 \mathrm{~min}$ of 


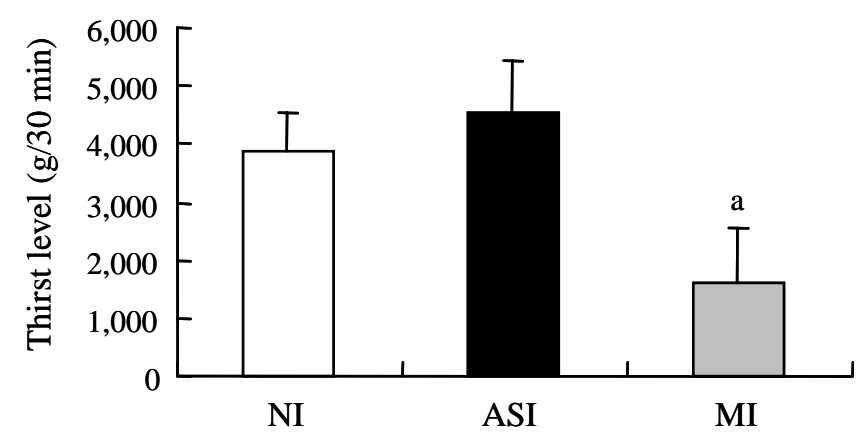

Figure 2. The effects of intravenous infusion of artificial parotid saliva (ASI) or iso-osmotic mannitol solution (MI) on water intake. Values are means \pm SE of 7 parotid fistulated goats. a: Means with superscript a differ $(\mathrm{p}<0.05)$ from non-infusion control (NI).

feeding (0 to $10 \mathrm{~min}, 464 \mathrm{~g} / 10 \mathrm{~min} ; 20$ to $30 \mathrm{~min}, 65 \mathrm{~g} / 10$ min). However, eating rates in the ASI and MI treatments were decreased more slowly over the first $30 \mathrm{~min}$ than those in the NI control. Eating rates in the ASI and MI treatments at 10,20 and $30 \mathrm{~min}$ intervals after feeding were higher than those in the NI control, respectively. After 30 min of the feeding period had elapsed, there was very little difference among the NI control and both treatments.

In comparison with the NI control (1,030 $\pm 101.4 \mathrm{~g} / 2 \mathrm{~h})$, cumulative feed intakes in the ASI and MI treatments were

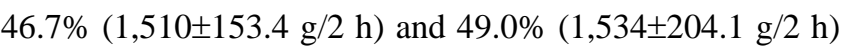
greater $(\mathrm{p}<0.05)$ upon conclusion of the $2 \mathrm{~h}$ feeding period. The majority of the cumulative feed intake increases recorded during the $2 \mathrm{~h}$ feeding period occurred in the first 30 min after the commencement of feeding.

\section{Water intake}

Figure 2 presents the effects of ASI or MI treatment on water intake after the completion of the $2 \mathrm{~h}$ feeding period. Water intake in the ASI treatment $(4,517 \pm 914 \mathrm{~g} / 30 \mathrm{~min})$ was not significantly different from that in the NI control $(3,858 \pm 679 \mathrm{~g} / 30 \mathrm{~min})$. Water intake in the MI treatment $(1,620 \pm 942 \mathrm{~g} / 30 \mathrm{~min})$ was, on the other hand, $58.0 \%$ lower $(\mathrm{p}<0.05)$ than that in the NI control.

\section{Plasma osmolality, plasma total protein concentration and hematocrit}

Figure 3 shows the effects of ASI or MI treatment on plasma osmolality, plasma total protein concentration and hematocrit in the blood sampled at $60 \mathrm{~min}$ before and 0,15 , 30, 45, 60, 90, 120, 150 and $165 \mathrm{~min}$ after feeding has commenced. Plasma osmolality very slowly increased in the control and both treatments over the first $1 \mathrm{~h}$ of the $2 \mathrm{~h}$ feeding period. Plasma osmolality in the ASI and MI treatments was not significantly different from that in the NI control during the first $1 \mathrm{~h}$ of the $2 \mathrm{~h}$ feeding period.
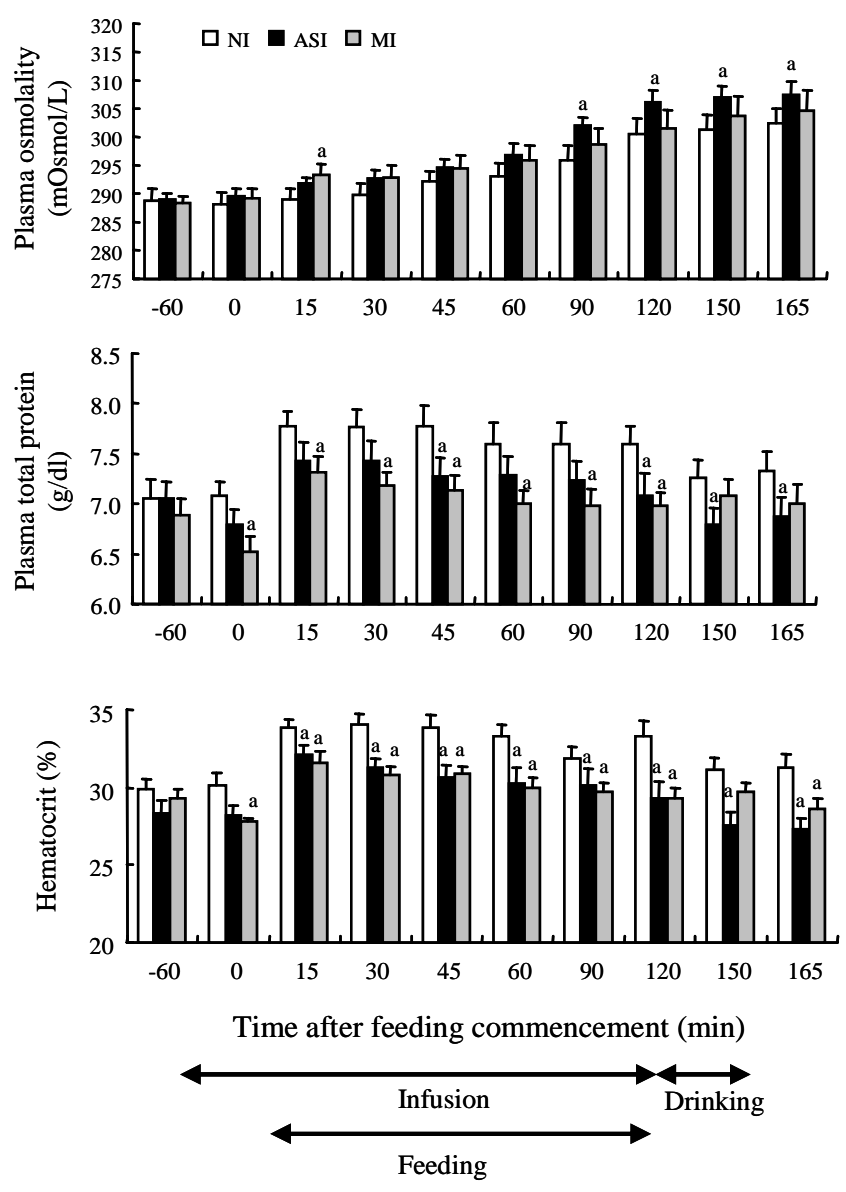

Figure 3. The effects of intravenous infusion of artificial parotid saliva (ASI) or iso-osmotic mannitol solution (MI) on plasma osmolality, plasma total protein concentration and hematocrit. Values are means \pm SE of 7 parotid fistulated goats. aMeans with superscript a differ $(\mathrm{p}<0.05)$ from non-infusion control $(\mathrm{NI})$.

In the control and both treatments, rapid increases in plasma total protein concentrations were recorded during the first $15 \mathrm{~min}$ after the commencement of feeding. Following this however, plasma total protein concentrations gradually decreased in both treatments for the remainder of the feeding period. Compared with the NI control, the ASI and MI treatments significantly $(\mathrm{p}<0.05)$ decreased plasma total protein concentration by $5.1 \%$ (4.2 to $6.8 \%$ ) and $7.7 \%$ (5.8 to $8.2 \%$ ), respectively during feeding.

The control and both treatments increased hematocrit markedly in the first 15 min after the commencement of feeding. Following this, hematocrit continued to gradually decrease in the control and both treatments for the remainder of the feeding period. Compared to the NI control, the ASI and MI treatment significantly $(\mathrm{p}<0.05)$ decreased hematocrit by $8.0 \%$ (5.2 to $11.8 \%$ ) and 8.8\% (6.6 to $10.0 \%$ ), respectively during feeding.

\section{Plasma concentrations of $\mathrm{Na}, \mathrm{K}$ and $\mathrm{Cl}$}

Figure 4 shows the effects of ASI or MI treatment on 

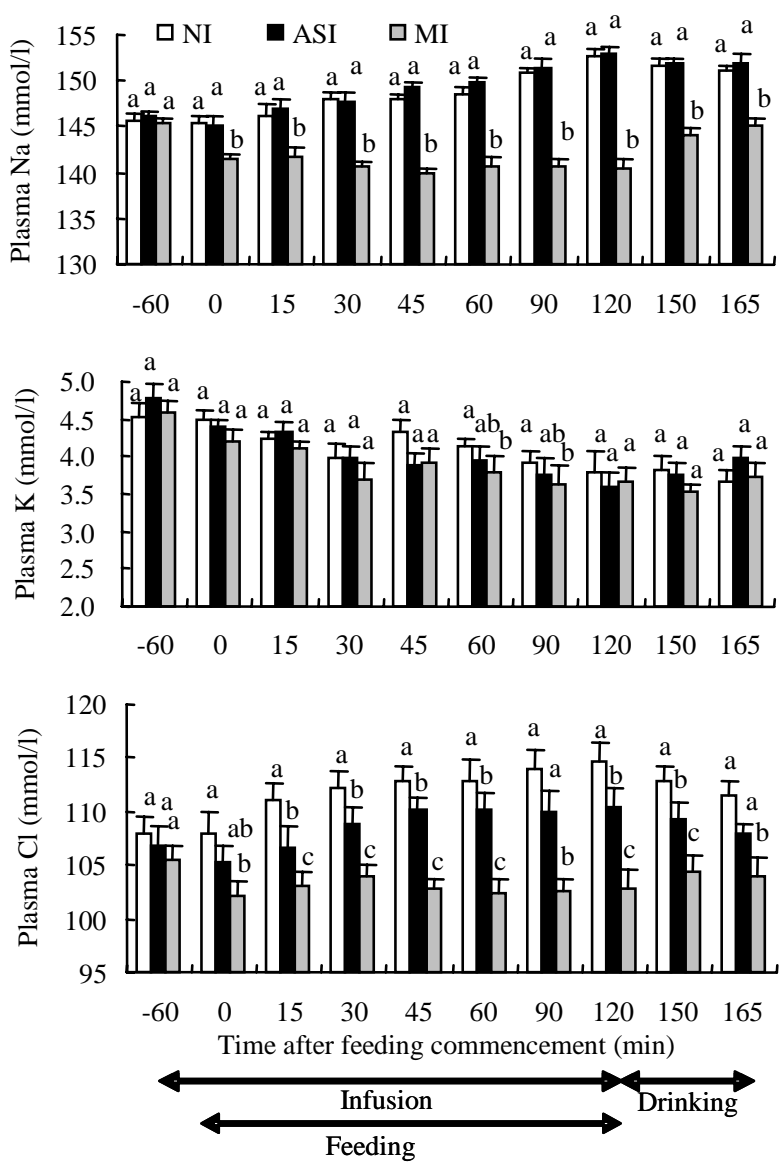

Figure 4. The effects of intravenous infusion of artificial parotid saliva (ASI) or iso-osmotic mannitol solution (MI) on plasma Na, plasma $\mathrm{K}$ and $\mathrm{Cl}$ concentration. Values are means \pm SE of 7 parotid fistulated goats. a,b: Means with superscripts a, b differ $(\mathrm{p}<0.05)$ from non-infusion control (NI).

plasma concentrations of $\mathrm{Na}, \mathrm{K}$ and $\mathrm{Cl}$. Plasma $\mathrm{Na}$ concentrations in the ASI treatment were not different from those in the NI control during the $2 \mathrm{~h}$ feeding period. However, plasma $\mathrm{Na}$ concentrations during feeding in the MI treatment were lower $(\mathrm{p}<0.05)$ than those in the NI control. Plasma $\mathrm{Cl}$ concentrations during feeding in the ASI and MI treatments were lower $(\mathrm{p}<0.05)$ than those in the NI control. Plasma $\mathrm{Cl}$ concentrations in the MI treatment were lower $(\mathrm{p}<0.05)$ than those in the ASI treatment.

The secretion rate of parotid saliva and cumulative parotid saliva secretion volume

Figure 5 shows the secretion rate of parotid saliva and cumulative parotid saliva secretion volume. The rates of parotid saliva secretion in the control and both treatments peaked in the first 10 min after feeding was commenced. These rates decreased as the feeding progressed. Saliva secretion rates in the ASI treatment very slowly decreased until 80 min of the feeding period had elapsed, while the rates observed in the NI control and MI treatment decreased more rapidly. The saliva secretion rates in the ASI treatment
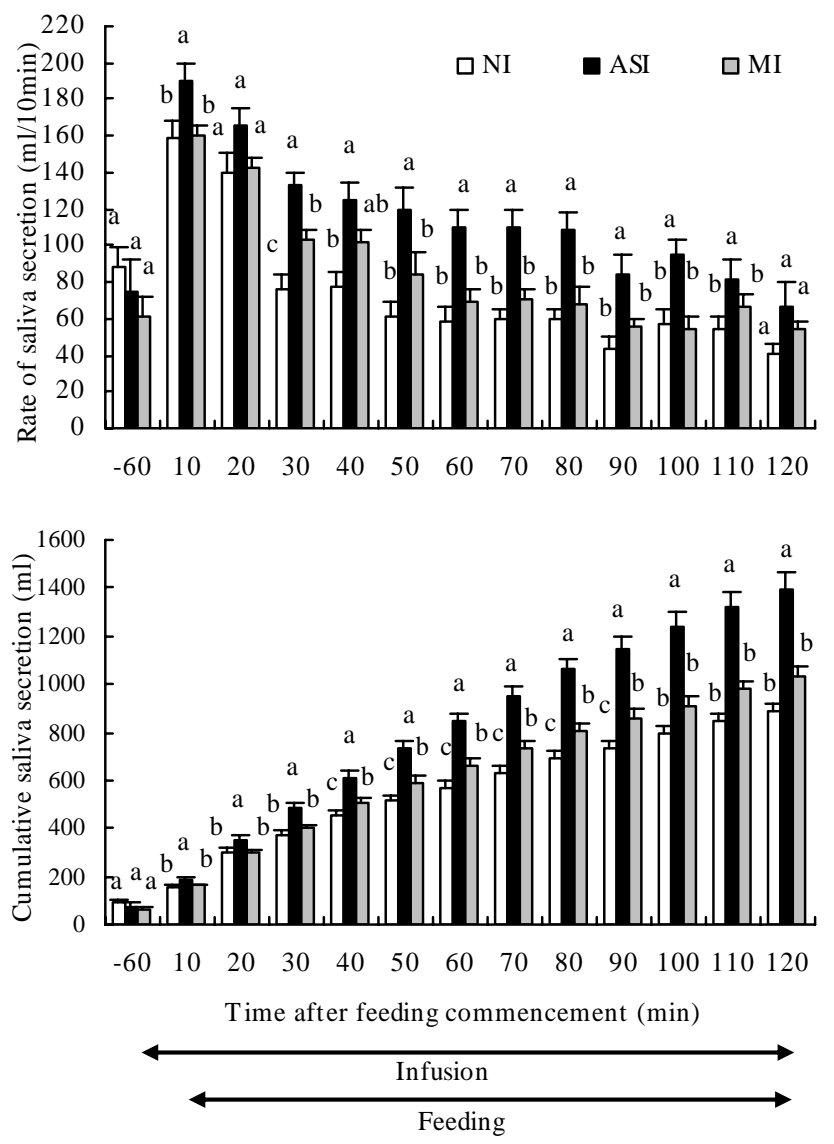

Figure 5. The effects of intravenous infusion of artificial parotid saliva (ASI) or iso-osmotic mannitol solution (MI) on rate of saliva secretion and cumulative saliva secretion. Values are means \pm SE of 7 paroted fistulated goats. a, b Means with superscripts a, b differ $(\mathrm{p}<0.05)$ from non-infusion control $(\mathrm{NI})$.

were markedly higher than those in the NI control and MI treatment for the entire $2 \mathrm{~h}$ duration of the feeding period. In comparison with the NI control, saliva secretion rates in the MI treatment were significantly $(\mathrm{p}<0.05)$ higher at 30 min after the commencement of feeding.

Compared to the NI control, the ASI treatment increased cumulative saliva secretion volume by $57.0 \%(\mathrm{p}<0.05)$, but the value in the MI treatment was not significantly different.

\section{Parotid saliva osmolality}

Figure 6 presents parotid saliva osmolality. Parotid saliva osmolalities in the ASI treatment increased slowly with feeding, while those in the NI control and MI treatment remained unchanged. Compared to the NI control, while the ASI treatment significantly increased $(\mathrm{p}<0.05)$ parotid saliva osmolalities during feeding, changes in the MI treatment were not significant. Parotid saliva osmolalities in the NI control (280.0 to $289.4 \mathrm{mOsm} / \mathrm{L}$ ) were significantly lower than plasma osmolalities (288.0 to $302.5 \mathrm{mOsm} / \mathrm{L}$, Figure 3). 


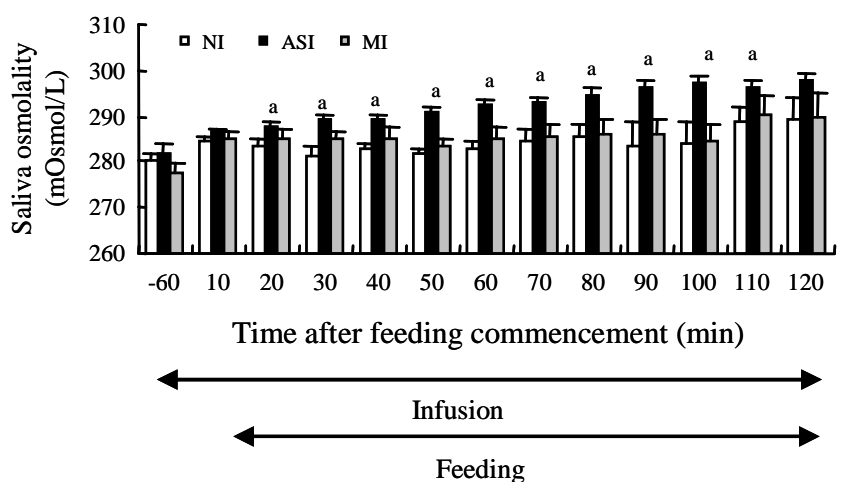

Figure 6. The effects of intravenous infusion of artificial parotid saliva (ASI) or iso-osmotic mannitol solution (MI) on saliva osmolality. Values are means \pm SE of 7 parotid fistulated goats. a: Means with superscript a differ $(\mathrm{p}<0.05)$ from non-infusion control (NI).

\section{DISCUSSION}

In countries such as Japan where ruminants are raised in barns, most farmers feed their stock a diet of dry roughage twice a day. In the present experiment, the goats were fed roughly crushed alfalfa hay cubes $(3 \times 3 \times 1 \mathrm{~cm})$ twice a day. Under such a feeding system, eating rates peaked in the first 10 min following the commencement of feeding. Following the peak, eating rates dropped dramatically to very low levels at $30 \mathrm{~min}$ (Figure 1). The mechanisms working to depress dry forage feeding in the first half of the feeding period have never been investigated.

When sheep and goats commence feeding on dry forage they secrete large volumes of saliva (Sato, 1975; Sunagawa, 2003). The saliva secreted by ruminants mainly consists of water and $\mathrm{NaHCO}_{3}$ (Tsuda, 1994). In the NI control of the present experiment, a decrease in plasma volume estimated by increases in hematocrit and plasma total protein concentrations was apparent within $15 \mathrm{~min}$ of the commencement of feeding (Figures 3 and 5). The plasma total protein concentrations throughout the entire $2 \mathrm{~h}$ feeding period in the NI control were observed to be higher than pre-feeding levels. It is thought that dry forage feeding induced hypovolemia was caused by the accelerated secretion of saliva during the initial stages of feeding.

Daily total mixed saliva secretion volumes are 6 to $16 \mathrm{~L}$ in sheep (Kay, 1960), and 98 to $190 \mathrm{~L}$ in cattle (Bailey, 1961). The bilateral glands contributing to the total mixed saliva secretion volumes are the parotid, submandibular, inferior molar, sublingual, buccal, labial, pharyngeal and palatine glands (Carter and Grovum, 1990). Parotid saliva secretion volumes in ruminants contribute $50 \%$ to $70 \%$ of the total mixed saliva secretion volumes (Tsuda, 1994). In ruminants, saliva secreted from the submandibular and sublingual glands is mucous and hypo-osmotic, while saliva secreted from the parotid and buccal glands is alkaline and iso-osmotic (Tsuda, 1994). As parotid saliva secretion increases during the initial stages of feeding, $\mathrm{NaHCO}_{3}$ and water are lost from the blood in the form of saliva. In the present experiment, the plasma total protein concentrations and hematocrits also increased within $15 \mathrm{~min}$ of the commencement of feeding in the ASI and MI treatments (Figure 3). This indicates that i.v. volumes of each solution prior to feeding in the ASI and MI treatments were smaller than the total secretion volumes of mixed saliva. Therefore, it is thought that the ASI and MI treatments replenished the parts of the fluid or $\mathrm{NaHCO}_{3}$ lost from the blood in the form of saliva during the initial stages of dry forage feeding.

Plasma osmolalities in the ASI and MI treatments were not significantly different from that in the NI control during the first $1 \mathrm{~h}$ of the $2 \mathrm{~h}$ feeding period (Figure 3 ). On the other hand, increases in plasma total protein concentration and hematocrit due to dry forage feeding were significantly $(\mathrm{p}<0.05)$ suppressed by the ASI and MI treatments (Figure 3). This result indicates that the level of decreases of circulating plasma volume caused by feeding on dry forage was significantly reduced by the ASI and MI treatments. Prasetiyono et al. (2000) found that plasma volume was involved in the decrease of dry matter intake in waterdeprived goats. It was found that there was a significant positive regression between plasma volume and cumulative feed intake after the completion of the $2 \mathrm{~h}$ feeding period. Angiotensin II (ANG II) is produced in the blood and vasopressin is secreted when circulating plasma volume decreases and plasma osmolality increases in rats and sheep (Blair-West and Brook, 1969; Fitzsimons, 1979; Mathai et al., 1997). Sunagawa et al. (2001) reported that intracerebroventricular infusion of ANG II decreased feed intake in sheep. Meyer et al. (1989) indicated that intraperitoneal injection of vasopressin decreased feed intake in goats. In the present experiment, because of the accelerated secretion of saliva during the initial stages of dry forage feeding, we found that when the components lost from the blood in the form of saliva were replenished, the degree of feeding suppression was lessened (Figures 1 and 5). From these reports, it is thought that the marked suppression of eating rates during the initial stages of dry forage feeding in the present experiment was brought about by a feeding induced hypovolemia.

Saliva is continuously lost in parotid fistulated sheep. So long as the saliva, lost through the parotid fistula was not returned to the body, sodium bicarbonate and water intake in the fistulated sheep markedly increased while feed intake and urine volumes decreased (Sunagawa et al., 2002b). In the present experiment, in order to avoid these influences on the animals, the saliva collected from the parotid fistula throughout the previous day was infused into the rumen prior to morning feeding every day. Among the goats used in this experiment, water intake and urine 
excretion recorded after parotid gland fistulation were not significantly different from values recorded prior to fistulation (Table 1). There were also no significant differences between values recorded prior to and after parotid gland fistulation in plasma osmolality, plasma total protein concentration, plasma sodium concentration and plasma chloride concentration (Table 1). These results indicate no change in the physiological state of the goats used in this experiment after fistulation.

When animals feed, chemical and mechanical stimuli work to stimulate the sensory nerves in the mouth and the afferent nerves in the esophagus and the stomach (Tsuda, 1994). These signals are transmitted to the salivary secretion center of the medulla oblongata. This in turn stimulates the efferent nerves which causes saliva secretion. The pattern of change in parotid saliva secretion rates in the NI control of the present experiment was similar to eating rates (Figures 1 and 5). This indicates that saliva secretion in goats is basically controlled by neural reflex. However, it was reported that the secretion rate of saliva in the ruminants was also controlled by some humoral factors. Sato (1975) indicated that the parotid saliva secretion rate in sheep was suppressed dramatically by intravenous injections of hypertonic $\mathrm{NaCl}$ solution (4.38\%) and mannitol solution (27.33\%). Warner and Stacy (1977) reported that intravenous infusion of hypertonic solutions, causing elevation of the osmotic pressure of the blood without affecting that of the rumen, caused a reduction of the secretion rate of mixed saliva in sheep. Sato (1975) suggested that post-feeding parotid saliva secretion rate was significantly suppressed by increases in plasma osomolality in parotid fistulated sheep fed on roughly crushed alfalfa hay cubes once a day. While the increases in plasma osmolality associated with feeding in the NI control were very gradual, plasma osmolality at the conclusion of the $2 \mathrm{~h}$ feeding period was significantly higher than the pre-feeding level (Figure 3). When compared to pre-feeding levels, plasma $\mathrm{Na}$ and $\mathrm{Cl}$ concentrations in the NI control of this experiment were observed to be higher at the conclusion of the $2 \mathrm{~h}$ feeding period (Figure 4). Stacy and Warner (1966), and Warner and Stacy (1972) reported that increases in plasma $\mathrm{Na}$ and $\mathrm{Cl}$ concentrations in sheep during feeding were dependent upon the continuous absorption of $\mathrm{Na}$ and $\mathrm{Cl}$ from the rumen. Tsuda (1994) reported that the majority of plasma osmolality is derived from electrolytic osmolality of $\mathrm{Na}, \mathrm{K}$ and $\mathrm{Cl}$. Based on these reports, it is thought that depression of post-feeding saliva secretion in ruminants is caused by increases in plasma osmolality due to the absorption of $\mathrm{Na}$ and $\mathrm{Cl}$ electrolytes from the rumen.

In the NI control of the present experiment, parotid saliva secretion rates markedly increased during the initial stages of feeding but had significantly decreased by the time 30 min of the feeding period had elapsed. Secretion rates remained at a constant low level for the remainder of the feeding period (Figure 5). Sunagawa et al. (2002a) reported that when parotid fistulated sheep fed on roughly crushed alfalfa hay cubes twice a day were intra-ruminally infused with warm water $\left(5 \mathrm{~L}, 36^{\circ} \mathrm{C}\right)$ prior to morning feeding, plasma osmolality and parotid saliva secretion rates recorded during the feeding period were not affected. However, Sunagawa et al. (2003) reported that the intraruminal infusion of parotid saliva $(5 \mathrm{~L})$ prior to feeding in goats under the same feeding conditions brought about an increase in plasma osmolality, and significantly suppressed parotid saliva secretion rates. On the other hand, in the present experiment (Figure 5), because of the accelerated secretion of saliva during the initial stages of dry forage feeding, we found that when the components lost from the blood in the form of saliva were intravenously replenished, plasma osmolality was not affected while the level of parotid saliva secretion suppression was significantly reduced. From the results, it is thought that plasma osmolality is not one of the physiological factors involved in the suppression of parotid saliva secretion rates during the initial stages of feeding in goats fed on dry forage. Denton (1956) reported that when $\mathrm{NaHCO}_{3}$ was withheld for a period of 10 days from parotid fistulated sheep fed on lucerne chaff once a day, the animals began showing signs of sodium depletion and saliva secretion volumes decreased. McKinley et al. (1979) reported that intravenous infusion of angiotensin II over the dose range 3-20 $\mu \mathrm{g} / \mathrm{h}$ for $15 \mathrm{~min}$ caused a dose dependent reduction in parotid saliva secretion in sheep.

Mannitol solution itself has no physiological activities and the solution was intravenously infused to replenish only the fluid lost from the blood in the form of saliva in the present experiment. Therefore, it is thought that the production of angiotensin II in the blood during the initial stages of dry forage feeding was inhibited in the MI treatment of the present experiment. Additionally, the intravenous infusion of iso-tonic mannitol solution caused a significant decrease in plasma $\mathrm{Na}$ and $\mathrm{Cl}$ concentrations due to dilution. However, the infusion had no effect on plasma osmolality (Figures 3 and 5). Eating provides stimulation in the mouth which promotes saliva secretion. However, cumulative parotid saliva secretion volumes in the present experiment after 50 min of the feeding period had elapsed had significantly increased in the ASI treatment (43\%) while the MI treatment showed only a $15 \%$ increase compared to the NI control (Figure 5). It is thought that the reason that the level of saliva secretion suppression during feeding in the MI treatment of the present experiment was so low was because the losses of $\mathrm{NaHCO}_{3}$ from the blood were not replenished during the initial stages of feeding. The results of the present experiment indicate that the marked suppression of saliva secretion during dry forage 
feeding is associated with the loss of $\mathrm{NaHCO}_{3}$ from the blood as a result of accelerated saliva secretion during the initial stages of feeding.

At the completion of the $2 \mathrm{~h}$ feeding period, water intake in the ASI treatment was no different in comparison to the NI control while water intake in the MI treatment significantly decreased (Figure 2). Because the cumulative feed intake recorded over the duration of the $2 \mathrm{~h}$ feeding period in the ASI and MI treatments was the same, it is estimated that the level of $\mathrm{Na}$ and $\mathrm{Cl}$ electrolyte absorption from the rumen was also the same (Stacy and Warner, 1966). On the other hand, despite the same volume of iso-osmotic solution being intravenously infused in both the ASI and MI treatments, cumulative parotid saliva secretion in the ASI treatment was significantly higher than the MI treatment (Figure 5). Despite equal increases in plasma volumes in both the ASI and MI treatments due to the intravenous infusion of the iso-osmotic solution, the plasma $\mathrm{Na}$ and $\mathrm{Cl}$ concentrations in the ASI treatment were markedly higher than the MI treatment (Figure 4). This can be attributed to the mineral content replenishing effect of artificial parotid saliva i.v. infusion in the ASI treatment (Figures 3, 4 and 5). It is thought that the reason decreases in water intake in the ASI treatment were not observed was due to losses of fluid from the blood caused by increased saliva secretion throughout the entire $2 \mathrm{~h}$ feeding period.

In conclusion, the present results indicate that the marked suppression of feed intake during the initial stages of dry forage feeding was caused by a feeding inducedhypovolemia while the suppression of saliva secretion was brought about by loss of $\mathrm{NaHCO}_{3}$ from the blood due to increased saliva secretion during the initial stages of feeding.

\section{ACKNOWLEDGEMENT}

The authors wish to thank Mr. Y. Murase and Miss R. Hazama for helpful assistance in collecting samples and analyzing the data. We thank G. McIlvride for help in preparing the manuscript. This research was partly supported by a Grant-in-Aid for Exploratory Research of the Ministry of Education, Science, Sports and Culture in Japan (No. 14560237).

\section{REFFERENCES}

Anil, M. H., J. N. Mbanya, H. W. Symonds and J. M. Forbes. 1993. Responses in the voluntary intake of hay or silage by lactating cows to intraruminal infusions of sodium acetate, sodium propionate or rumen distension. Br. J. Nutr. 69:699-712.

AOAC. 1990. Official Methods of Analysis. $15^{\text {th }}$ ed. Assoc. Off. Anal. Chem. Arlington, VA.

Baile, C. A., J. Mayer and C. L. McLaughlin. 1969. Feeding behavior of goats: ruminal distention, ingesta dilution and acetate concentration. Am. J. Physiol. 217:397-402.
Bailey, C. B. 1961. Saliva secretion and its relation to feeding in cattle. 3. The rate of secretion of mixed saliva in the cow during eating, with an estimate of the magnitude of the total daily secretion of mixed saliva. Br. J. Nutr. 15:443-451.

Blair-West, J. R. and A. H. Brook. 1969. Circulatory changes and renin secretion in sheep in response to feeding. J. Physiol. 204:15-30.

Campling, R. C. and C. C. Balch. 1961. Factors affecting the voluntary feed intake of the cow. 1. Preliminary observations on the effect, on the voluntary intake of hay, of changes in the amount of the reticulo-ruminal contents. Br. J. Nutr. 15:523530.

Carter, R. R. and W. L. Grovum. 1990. A review of the physiological significance of hypertonic body fluids on feed intake and ruminal function: salivation, motility and microbes. J. Anim. Sci. 68:2811-2832.

Denton, D. A. 1956. The effect of $\mathrm{Na}^{+}$depletion on the $\mathrm{Na}^{+}: \mathrm{K}^{+}$ ratio of the parotid saliva of the sheep. J. Physiol. 131:516-525.

Fitzsimons, J. T. 1979. The physiology of thirst and sodium appetite. Cambridge University Press, Cambridge, UK.

Forbes, J. M. and J. P. Barrio. 1992. Abdominal chemo- and mechano-sensitivity in ruminants and its role in the control of food intake. Exp. Physiol. 77:27-50.

Grovum, W. L. 1995. Mechanisms explaining the effects of short chain fatty acids on feed intake in ruminants-osmotic pressure, insulin and glucagons. Ruminant Physiology: Digestion, Metabolism, Growth and Reproduction. Proceedings of the 8th International Symposium on Ruminant Physiology, (Ed. W. V. Engelhardt, S. Leonhard-Marek, G. Breves and D. Giesecke). Ferdinand Enke Verlag, Stuttgart. pp. 137-197.

Hidari, H. 1981. The relationships between rumen load and diurnal eating pattern of sheep fed on various time of access to feed. Jpn J. Zootech. Sci. 52:219-226.

Kato, S. 1977. Experimental studies with regard to factors controlling feed intake in sheep. Ph.D. Thesis, Tohoku University, Sendai, Japan.

Kato, S., Y. Sasaki and T. Tsuda. 1979. Food intake and rumen osmolality in the sheep. Annales de Recherches Veterinaire. 10:229-230.

Kato, Y. 1988. Analysis of chemical components of feed. Shiryo Bunseki Kijun Tyukai, Japanese Feed Association, Tokyo, Japan, pp. 1-16.

Kay, R. N. B. 1960. The rate of flow and composition of various salivary secretions in Sheep and calves. J. Physiol (Lond.). 150:515-537.

Mathai, M., M. D. Evered and M. J. McKinley. 1997. Intracerebroventricular losartan inhibits postprandial drinking in sheep. Am. J. Physiol. 272:R1055-R1059.

McKinley, M. J., D. A. Denton, S. Hatzikostas and R. S. Weisinger. 1979. Effect of angiotensin II on parotid saliva secretion in conscious sheep. Am. J. Physiol. 237:E56-E60.

Meyer, A. H., W. Langhans and E. Scharrer. 1989. Vasopressin reduces food intake in goats. Q. J. Exp Physiol. Cogn. Med. Sci. 74:465-473.

Prasetiyono, B. W. H. E., K. Sunagawa, A. Shinjo and S. Shiroma. 2000. Physiological relationship between thirst level and feed intake in goats fed on alfalfa hay cubes. Asian-Aust. J. Anim. Sci. 13:1536-1541.

Sasaki, Y., S. Watanabe, Y. Satoh, S Kato and T. Tsuda. 1974. 
Changes in acid-base status of sheep during eating. Jpn. J. Sunagawa, K., R. S. Weisinger, M. J. McKinley, B. S. Purcell, C. Zootech Sci. 45:8-13.

Sasaki, Y., S. Watanabe, Y. Satoh and S. Kato. 1975. Effect of intravenous infusion of artificial saliva on changes in acid-base status of sheep during eating. Jpn. J. Zootech Sci. 46:449-453.

Sato, Y. 1975. The relationship between saliva secretion and body fluid balance during feeding. Ph. D. Thesis Tohoku University, Sendai, Japan.

Stacy, B. D. and A. C. I. Warner. 1966. Balances of water and sodium in the rumen during feeding: osmotic stimulation of sodium absorption in the sheep. Q. J. Exp. Physiol. 51:65-78.

Sunagawa, K., R. S. Weisinger, M. J. McKinley, B. S. Purcell, C. Thomson and P. L. Burns. 2001. The role of angiotensin II in the central regulation of feed intake in sheep. Asian-Aust. J. Anim. Sci. 14:215-221.

Sunagawa, K., Y. Nakatsu, Y. Nishikubo, T. Ooshiro, K. Naitou and I. Nagamine. 2002a. Effects of intraruminal saliva flow on feed intake in goats fed on alfalfa hay cubes. Asian-Aust. J. Anim. Sci. 15:1738-1746. Thomson and P. L. Burns. 2002b. Effect of intracerebroventricular infusion of urocortin on feed and salt intake in parotid fistulated sheep. Anim. Sci. J. 73:35-40.

Sunagawa, K., Y. Nakatsu, Y. Nishikubo, T. Ooshiro, K. Naitou and I. Nagamine. 2003. Effect of parotid saliva secretion on dry forage intake in goats. Asian-Aust. J. Anim. Sci. 16:11181125.

Tsuda, T. 1994. Digestion and absorption. In: Animal Physiology, Youkendo, Tokyo, Japan, p. 149.

Van Soest, P. J., J. B. Robertson and B. A. Lewis. 1991. Methods for dietary fiber, neutral detergent fiber, and nonstarch polysaccharides in relation to animal nutrition. J. Dairy Sci. 74:358-3597.

Warner, A. C. and B. D. Stacy. 1972. Water, sodium and potassium movements across the rumen wall of sheep. Q. J. Exp. Physiol. 57:103-119.

Warner, A. C. and B. D. Stacy. 1977. Influence of ruminal and plasma osmotic pressure on salivary secretion in sheep. Q. J. Exp. Physiol. 57:103-119. 